\title{
Compreensão em Leitura e Avaliação da Aprendizagem em Universitários
}

\author{
Katya Luciane de Oliveira ${ }^{1}$ \\ Acácia Aparecida Angeli Dos Santos \\ Universidade São Francisco
}

\begin{abstract}
Resumo
Este estudo teve por objetivo explorar a relação entre a compreensão em leitura, o desempenho acadêmico e a avaliação da aprendizagem em disciplinas específicas. A amostra foi composta por 270 alunos ingressantes dos cursos de administração, direito e psicologia, dos períodos diurno e noturno, de uma universidade particular do interior paulista. Os instrumentos utilizados foram 2 textos preparados segundo a técnica de Cloze e um questionário visando a caracterização dos tipos mais freqüentes de avaliação utilizados no ensino superior. A participação dos estudantes foi voluntária e a coleta de dados ocorreu de forma coletiva em uma única sessão. Os resultados evidenciaram que há correlação estatisticamente significativa entre a compreensão em leitura, o desempenho acadêmico e o tipo de avaliação da aprendizagem utilizado.

Palavras-chave: Teste de Cloze; rendimento acadêmico; ensino superior.
\end{abstract}

\section{Reading Comprehension and Learning Evaluation among Undergraduates}

\begin{abstract}
This research meant to explore the relation among reading comprehension, academic performance and learning assessment in specific contents. The sample was composed of by 270 freshman students from administration, law and psychology courses, from daytime and evening period in a private university in São Paulo. The instruments used were 2 texts prepared in accordance to Cloze's technique and a questionnaire focusing the most used characterization types in higher education assessment. The students' participation was voluntary and the data collect happened in a collective session form. The results showed clearly a correlation, statistically significant, among reading comprehension, academic performance and learning assessment was conclusive.

Keywords: Cloze's test; academic performance; higher education.
\end{abstract}

Diariamente, identificam-se várias situações que requerem o uso da habilidade de leitura. No mundo moderno inúmeras tarefas dependem dela, desde pegar o ônibus certo, até ler uma bula de remédio corretamente. A leitura está presente em muitos momentos do cotidiano das pessoas. Nesse sentido, Teberosky e Cardoso (1993) advertem que a sociedade urbana contribui, em muito, para que os conhecimentos lingüísticos ocorram por meio de recursos como out-doors, televisão, jornais, entre outros meios de comunicação, o que demonstra que a escrita e a leitura não estão restritas à atividade escolar.

Ler é uma habilidade que faz parte do nosso dia-a-dia, entretanto, por mais comum que possa parecer a realização de uma leitura, essa tarefa não é tão simples como pode ser julgada. A leitura pode ser sinônimo de apenas decifrar os signos do alfabeto, juntar as palavras e sentenças e esse tipo de leitura é suficiente para que haja o mínimo de comunicação entre as pessoas. Porém, dentro de uma visão mais abrangente, ler significa, fundamentalmente, compreender o que foi lido. Não basta somente decodificar, é preciso que o leitor se contextualize e atribua significado à sua leitura. Quando um leitor atinge esse nível de compreensão é considerado fluente ou proficiente, desde que também sejam agregadas outras habilidades relevantes, tais como, a velocidade, a criticidade, a criatividade e a motivação (Kopke Fo , 2001; Santos, 1990a; Vicentelli, 1999).

Atualmente, embora haja a preocupação crescente com o desenvolvimento dos conhecimentos relacionados à leitura, a

${ }^{1}$ Endereço para correspondência: Rua Maestro Sebastião Peranovich, 415, Atibaia, Jardim Atibaia, São Paulo, 12940 000, Fone: (11) 44119773. E-mail: katya_lincoln@ig.com.br produção sobre o tema ainda é muito pequena. Com a preocupação de levantar a produção de pesquisas sobre leitura, Witter (1997) fez uma análise do Annual Summary of Investigations Relating to Reading (Summary) e comparou com a produção brasileira, concluindo que no Brasil há poucas pesquisas sobre leitura. A autora atribui a escassez de pesquisas à falta de incentivos, de cursos específicos e de docentes especializados, diferentemente da produção estrangeira, principalmente a de países mais desenvolvidos, onde estudos sobre leitura estão em ascensão e evidência. Outro aspecto apontado é que em países, nos quais a tradição de pesquisa em leitura é limitada e com poucos investimentos financeiros, há a importação de modismos que, muitas vezes, não possuem fundamentação teórica e metodológica. Esses modelos causam na educação efeitos nefastos que atrasam ainda mais a evolução do conhecimento na área.

Com a preocupação de investigar a produção em leitura, Carelli (2002) realizou uma pesquisa sobre a produção científica nas áreas de educação e psicologia, analisando dissertações e teses apresentadas em quatro universidades paulistas (PUC-São Paulo, PUC-Campinas, UNICAMP e USP) entre os anos de 1990 e 1999 e no Dissertation Abstracts International (DAI). Dentre as conclusões apontadas, constatase o alerta para o fato de que, mesmo nas instituições de grande mérito acadêmico, a produção ainda é muito pequena na área de leitura.

Mesmo que a realidade remeta a uma conclusão desanimadora quanto ao crescimento de pesquisas nessa área, não se deve medir esforços para ampliar a gama de conhecimento sobre o assunto. É sabido que a leitura representa um grande passo para aquisição do 
conhecimento, pois é por meio dela que se adquire uma percepção singular do mundo. Além disso, oferece também uma contribuição no funcionamento e desenvolvimento do pensamento crítico, levando o leitor a questionar e avaliar o texto lido, dentro de um referencial próprio de seus conhecimentos, conceitos e valores (Drouet, 1995; Ellis, 1995; Gregoire \& Piérart, 1997; Santos,1990a, 1990b, 1990c).

É inquestionável a responsabilidade da leitura em uma educação de qualidade, mas as evidências apontam que diversos alunos saem do ensino fundamental e médio sem essa habilidade. Tais alunos ingressam no ensino superior com sérias deficiências no comportamento de leitura (Garrido, 1988). Fato lastimável, pois no ensino universitário a leitura é primordial, visto que ela dará ao estudante subsídios para o desenvolvimento crítico, cultural e técnico necessário na sua formação.

Considerando esse contexto, a universidade tem o dever de proporcionar ao estudante uma formação que lhe propicie condições de desenvolver uma leitura eficaz, principalmente no que tange à leitura técnico-científica, que é primordial ao futuro desempenho profissional desse estudante (Witter, 1996, 1997). A habilidade de leitura é essencial para o estudante universitário, conforme observa Santos (1991), pois seu sucesso no ensino superior está associado à sua maturidade em leitura, que pode ser melhorada, se diagnosticada apropriadamente. Assim, o papel da universidade é planejar, desenvolver e administrar programas de superação das limitações relacionadas à dificuldade de leitura.

Centofanti, Ferreira e Del Tedesco (1997) consideram que as universidades deveriam dar maior importância à leitura e tornarem o professor universitário co-responsável pela tarefa de orientar seus alunos no aperfeiçoamento dessa habilidade. Witter (1997) lembra que o docente universitário também merece atenção no desenvolvimento da sua própria habilidade de leitura, posto que é básica para o seu trabalho, quer seja para o seu desenvolvimento pessoal, quer seja como ferramenta de trabalho. Sendo um leitor hábil e apresentando excelência nos vários níveis e tipos de leitura, o docente-leitor poderá influenciar positivamente o comportamento do aluno-leitor.

Embora seja papel do ensino universitário proporcionar uma visão mais crítica em relação ao mundo, diversos estudos têm evidenciado que estudantes universitários não apresentam o nível de leitura esperado para essa etapa de escolarização (Carelli, 1996; Oliveira, 1996; Pellegrini, 1996; Santos, 1990a). Desse modo, tornase relevante a realização de estudos e pesquisas que busquem alternativas para o diagnóstico e o desenvolvimento dessa habilidade.

Nesse sentido, esta pesquisa nasce com base em algumas hipóteses levantadas em um trabalho de conclusão de curso realizado por Oliveira (2001). A autora pesquisou a relação entre compreensão em leitura e desempenho acadêmico, sendo que das 12 correlações estudadas, apenas 6 foram significativas. Chamou a atenção o fato de que o desempenho acadêmico em disciplinas que requeriam grande quantidade de leitura (antropologia, filosofia, história da psicologia, metodologia científica e psicologia geral) não tenha sido encontrado uma correlação significativa com o desempenho no teste de Cloze, utilizado como instrumento de avaliação do nível de compreensão em leitura dos alunos.

Com base na análise dos resultados obtidos por Oliveira (2001), levantou-se como hipótese que a baixa relação entre a compreensão de leitura e o desempenho acadêmico nessas disciplinas poderia estar relacionada ao tipo de avaliação feita pelo professor, que possivelmente eram discrepantes em relação ao tipo de exigência requerida. Desse modo, além das variáveis estudadas na ocasião, surgiu outra variável que mereceria ser objeto de estudo, a saber, o tipo de estratégia de avaliação utilizada, que será focalizada na presente pesquisa.

\section{A avaliação da aprendizagem e suas implicações no ensino superior}

Segundo Almeida (1992, 1997), a palavra avaliação possui diversos significados advindos de muitas concepções e, como por exemplo, apreciação, análise, estimação, determinação de valor, diagnóstico, controle, classificação, entre outros. No entanto, há que haver uma clareza na diferença existente entre técnica e instrumento. A técnica deve ser entendida como um meio que informa o que se pretende em uma avaliação, ou seja, como o avaliador procede. $\mathrm{O}$ instrumento corresponde ao recurso utilizado na avaliação, que pode assumir características específicas e exigir diferentes habilidades do aluno, como por exemplo, as requeridas em um teste objetivo ou numa prova dissertativa. Qualquer que seja a metodologia de ensino adotada, não há como utilizar ou dar maior importância a um único modo de avaliar, visto que se um professor restringe-se apenas um instrumento de avaliação o resultado poderá não ser confiável, ficando restrito a um momento exclusivo e a uma única forma de aferir o conhecimento do estudante.

Observa-se que a função da avaliação, conforme salienta Gronlund (1979), é aperfeiçoar métodos, estratégias e materiais, visando o aprimoramento da aprendizagem do aluno e a melhora do ensino do professor, possibilitando a comunicação entre professor e aluno. A avaliação deve ter como principal função, por um lado, orientar o professor quanto ao aperfeiçoamento de sua metodologia e, por outro, possibilitar a melhora do desempenho do aluno.

Franco (1997) considera que o processo avaliativo pode ser classificado de acordo com dois tipos. O primeiro é chamado processo avaliativo objetivo, que tem seus critérios fundamentados na cientificidade, observação, verificação e experimentação. Nesse modelo há uma sofisticação nos procedimentos avaliativos que utiliza escalas, inventários e testes padronizados para apurar os resultados. O segundo, denominase processo avaliativo subjetivo e surge da crítica ao primeiro modelo, professando que ao avaliar há de se respeitar ao ritmo individual de cada pessoa, visto que cada um aprende de modo diferente. A autora considera a objetividade como algo parcial e valoriza a auto-avaliação como medida mais confiável de avaliação, ressaltando que os processos avaliativos, objetivos e subjetivos, são insuficientes como medida de realidade. 
É consenso entre muitos estudiosos da área que não há como ignorar o contexto social do estudante, pois como lembram Sousa (1997) e Kasai (2000) ele influi na avaliação da aprendizagem. O aluno traz um conhecimento social, construído ao longo de sua vida, que interfere em sua concepção de mundo e na sua aprendizagem. Ainda dentro de uma perspectiva social, a avaliação representa uma forma de discriminação ou classificação dos alunos, pois seleciona aqueles que serão capazes de prosseguir nas séries subsequentes. Muitas vezes os eliminados são aqueles advindos de classes sociais menos favorecidas, que são excluídos do sistema, pois não há uma interação entre a escola e as condições sociais específicas vividas pelo aluno. Vista por esse ângulo, a avaliação funciona como uma ferramenta que viabiliza a exclusão.

Para Esteban (2000), a avaliação está relacionada à quantificação do conhecimento do aluno, que, transformada em nota, inevitavelmente leva à classificação, seleção e ao controle de comportamento, justificando a exclusão. A nota final da avaliação da aprendizagem, para Depresbiteris (1997), tem uma conotação administrativa, descartando o papel de orientação para melhoria do desempenho do professor e do aluno. Assim, a nota funciona como instrumento de poder na relação professor/aluno e tem uma função meramente burocrática, não refletindo necessariamente a aprendizagem ocorrida. Nesse sentido, para que a avaliação seja eficaz, deveria enfatizar o processo utilizado para alcançar o objetivo e não apenas o resultado final do trabalho do aluno. Mas, o que se observa é que a avaliação tem um caráter de atribuição de valor, pois, por meio dela, o docente é capaz de mensurar o desempenho do aluno, inclusive desconsiderando os objetivos da disciplina e o projeto pedagógico do curso.

Silva (2001) acredita que a avaliação da aprendizagem pode ser considerada positiva, quando é empregada com o objetivo de análise de uma prática educativa integradora. Ressalta que a avaliação deveria possibilitar ao estudante a percepção e a superação de suas dificuldades, o que atribuiria ao processo avaliativo a necessária conotação investigativa. O professor, como parte integrante do sistema de avaliação, deveria basear-se em um julgamento dos resultados, comparando o que pretendia alcançar com o que foi realmente alcançado. Com isso, professor e aluno poderiam rever suas metas e se aperfeiçoarem cada vez mais, para que um e outro, caminhassem em direção ao conhecimento desejável.

No que tange à avaliação e à nota, Kasai (2000) destaca que ambas ocupam um lugar de destaque na vida de qualquer estudante, principalmente dos estudantes universitários, que vivem em 'busca de nota'. Porém, Almeida (1992) e Martins (1999) observam que a avaliação no ensino superior é sinônimo de uma convivência tumultuada entre experiências tradicionais de ordem classificatória e tendências de procedimentos renovadores. De forma geral, os docentes têm dificuldades em serem coerentes quanto ao tipo de avaliação e o aluno torna-se um interlocutor passivo nessa relação conflituosa que se estabelece quanto ao tipo avaliação ao qual é submetido.

Além do aspecto objetivo, avaliar deveria se constituir em um momento reflexivo, pois, como observa Buriasco (2000), o papel mais importante da avaliação da aprendizagem é o de auxiliar a construção da aprendizagem do aluno. Avaliar a aprendizagem deveria servir como uma forma de guiar o processo de ensino, desde que realçado o aspecto positivo da avaliação que seria vivenciada pelo universitário como uma experiência que traz ganhos à sua formação. Camargo (1997) acredita que desta forma a avaliação propiciará o desenvolvimento individual, intelectual e social do aluno, pois enquanto for enfatizado o lado negativo dificilmente ocorrerá o desenvolvimento desejável das habilidades intelectuais do estudante.

Face às considerações realizadas, o objetivo do presente trabalho foi analisar a relação entre compreensão em leitura e o desempenho acadêmico resultante da avaliação da aprendizagem em disciplinas específicas de diferentes cursos superiores.

\section{Método}

\section{Participantes}

Participaram 270 alunos ingressantes de uma universidade particular do interior paulista, dos cursos de administração $(27,8 \% ; n=75)$, direito $(29,3 \% ; n=79)$ e psicologia $(43 \% ; n=116)$, sendo a maioria do período noturno $(88,9 \% ; n=240)$. A média de idade dos estudantes foi de 23 anos e 6 meses $(d p=6,73)$, variando de 17 a 53 anos. O gênero masculino representou 30,7\% $(n=83)$ do total de estudantes e o feminino $69,3 \%(n=187)$.

\section{Material}

- Questōes de identificação dos participantes - incluindo o nome, o registro acadêmico, a idade, o gênero, o curso e o turno.

- Teste de Cloze - foram utilizados dois textos adaptados, um de Luís Fernando Veríssimo, intitulado 'Desentendimento' (Cloze 1), cuja pontuação poderia variar de 0 a 46 acertos e o outro, de Carlos Heitor Cony, intitulado 'A nova classe dominante' (Cloze 2), cuja pontuação poderia variar de 0 a 40 acertos. Cada texto continha aproximadamente 250 vocábulos, do qual se omitiu sempre o $5^{\circ}$ vocábulo, sendo que o espaço deixado foi proporcional ao tamanho da palavra omitida.

- Questionário - incluiu questões fechadas, contendo as formas de avaliação mais comuns no ensino superior, a saber, apresentação de seminários em grupo, debates em sala de aula, estudos de caso, participação em sala de aula, provas dissertativas em grupo, provas dissertativas individuais, provas objetivas (testes) em grupo, provas objetivas (testes) individuais, provas orais em grupo, provas orais individuais, resenhas de livros, resumos de capítulos de livros, trabalhos dissertativos em grupo, trabalhos dissertativos individuais. Os alunos deveriam assinalar com um $\mathrm{X}$ as estratégias de avaliação das quais as notas nas disciplinas cursadas foram predominantemente obtidas. Além disso, havia uma questão aberta na qual o aluno deveria informar, para cada disciplina, qual o tipo de avaliação que ele julgaria ter sido seu desempenho melhor avaliado.

\section{Critérios de Avaliação}

Número de acertos obtidos nos dois textos preparados segundo a técnica de Cloze, cuja forma de correção foi literal, 
sendo que era atribuído um ponto para cada resposta idêntica à palavra omitida. Notas escolares, médias referentes a todas as disciplinas cursadas no primeiro semestre, considerando-se os conteúdos específicos de cada curso focalizado. Freqüência das respostas dadas pelos alunos no questionário de caracterização dos meios de avaliação.

\section{Procedimento}

As provas foram aplicadas em uma sessão, em horário de aula previamente cedida pelo professor, aos participantes que assinaram o termo de consentimento esclarecido. As notas foram obtidas na secretaria da instituição

\section{Resultados}

Para facilitar a análise de dados, principalmente no que concerne a relação entre compreensão em leitura e desempenho acadêmico, foi considerado para análise somente o Cloze total (somatória dos Clozes 1 e 2), considerando que os escores dos alunos nos dois textos apresentou índices de correlação estatisticamente significativos entre si $(r=0,460 ; p<0,001)$, bem como, o de cada um deles com o escore total, a saber, Cloze 1 $(r=0,913 ; p<0,001)$ e Cloze $2(r=0,782 ; p<0,001)$.

A Tabela 1 mostra os dados referentes às correlações entre os escore do Cloze e o desempenho acadêmico nos conteúdos específicos dos cursos de administração, direito e psicologia.

Dentre as 13 disciplinas que apresentaram correlações significativas com os escores do Cloze 23,1\% $(n=3)$ obtiveram um nível de significância determinado como 'significativo' $(p=0,05), 15,3 \%(n=2)$ obtiveram um nível de significância determinado como 'muito significativo' $(p=0,01)$ e $61,5 \%(n=8)$ obtiveram um nível de significância determinado como 'altamente significativo' $(p=0,001)$.

No que tange aos tipos de avaliação apontados pelos estudantes como os mais utilizados pelos docentes que ministram conteúdos específicos nos cursos analisados, os dados podem ser observados na Figura 1.

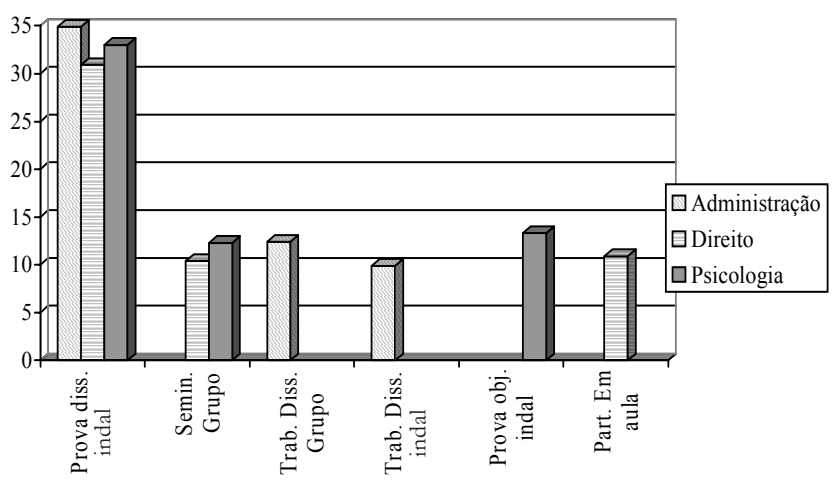

Figura 1. Distribuição do percentual de freqüência de opções por curso dos tipos de avaliação mais utilizados pelos professores.

Observou-se que nos três cursos prevalece a realização de avaliações individuais, considerando-se que no curso de administração foram realizadas $61,1 \%(n=11)$ de avaliações, cuja atividade era individual e $27,7 \%(n=5)$ de avaliações envolvendo atividades em grupo, o estudo de caso foi utilizado 11,1\% (n=2), porém não entrou em nenhuma das categorias (individual/ grupo), visto que não for possível determinar se a atividade foi

Tabela 1

Distribuição das Correlações entre o Escore do Cloze e o Desempenho Acadêmico nos Conteúdos Específicos dos Cursos Analisados $(\mathrm{N}=270)$

\begin{tabular}{lcc}
\hline Conteúdos específicos & $R$ & $p$ \\
\hline Administração & & \\
Comunicação empresarial & 0,540 & 0,000 \\
Introdução à administração & 0,283 & 0,015 \\
Matemática básica & 0,193 & 0,100 \\
Metodologia do trabalho científico & 0,462 & 0,000 \\
Projetos interdiciplinares de desenvolvimento profissional & 0,221 & 0,060 \\
Direito & & \\
Ciências políticas e teoria geral do estado & 0,358 & 0,001 \\
Direito civil I & 0,521 & 0,000 \\
Economia e noções de direito econômico & 0,436 & 0,000 \\
Introdução aos estudos de direito & 0,122 & 0,291 \\
Sociologia geral e jurídica & 0,270 & 0,017 \\
Psicologia & & \\
História da psicologia & 0,387 & 0,000 \\
Antropologia cultural & 0,238 & 0,010 \\
Fundamentos da psicologia e formação profissional & 0,450 & 0,000 \\
Filosofia & 0,259 & 0,005 \\
Psicologia geral & 0,400 & 0,000 \\
Citogenética & 0,383 & 0,000 \\
\hline
\end{tabular}


realizada individualmente ou em grupo. No curso de direito foram realizadas $56,2 \%(n=9)$ de avaliações individuais e $25 \%$ $(n=4)$ de avaliações em grupo, a participação em sala de aula foi utilizada 18,7\% $(n=3)$, mas não entrou em nenhuma das categorias, considerando que não havia como mensurar como essa participação foi avaliada. No curso de psicologia a porcentagem de avaliações individuais realizadas foi de $61,1 \%(n=11)$ e as avaliações em grupo representaram o total de $33,3 \%(n=6)$, a participação em sala de aula teve uma porcentagem de utilização de 5,5\% $(n=1)$, entretanto não entrou em nenhuma das categorias.

Para verificar a relação entre compreensão de leitura, desempenho acadêmico e tipo de avaliação utilizada em disciplinas específicas, recorreu-se à prova de correlação de Pearson. Os índices de correlação entre o desempenho acadêmico e os escores do Cloze foram correlacionados com as médias das porcentagens de escolha por tipo de avaliação. Os resultados podem ser observados na Tabela 2.

A análise dos resultados evidenciou que o nível de significância obtido não foi significativo, considerando-se a exigência de $p<0,05$. Todavia, observou-se que as disciplinas que exigiam uma produção escrita, ou seja, 'dissertar sobre' cujo trabalho era essencialmente individual, apresentavam uma tendência de se correlacionar positivamente aos coeficientes de correlação entre os escores do Cloze e do desempenho acadêmico. O inverso também foi observado, tendo em vista que as disciplinas cujo trabalho era realizado em grupo, apresentaram uma tendência de se correlacionar negativamente às variáveis.

Com base nessa constatação, os tipos de avaliação foram agrupados considerando o seguinte critério, o tipo de avaliação denominado estudo de caso foi excluído do agrupamento, tendo em vista que não foi possível determinar se a atividade foi realizada de forma individual ou em grupo. As provas objetivas em grupo e individual foram excluídas por não envolverem produção escrita e, por fim, o tipo classificado como participação em sala de aula, também foi excluído, pois não foi possível determinar como essa participação foi avaliada.

Tabela 2

Indices de Correlações (r) e Niveis de Significancias (p) entre os Coeficientes de Correlação do Cloze e o Desempenho Acadêmico e das Porcentagens de Citaçôes em cada tipo de Avaliação nos Cursos Analisados (N=270)

\begin{tabular}{lrc}
\hline Tipos de avaliação & $r$ & $p$ \\
\hline Estudo de caso & 0,037 & 0,893 \\
Prova dissertativa em grupo & $-0,102$ & 0,706 \\
Prova dissertativa individual & 0,183 & 0,498 \\
Resumo de livros/capítulos & 0,308 & 0,245 \\
Trabalhos dissertativos em grupo & $-0,308$ & 0,246 \\
Trabalhos dissertativos individuais & 0,401 & 0,123 \\
Prova objetiva em grupo & 0,269 & 0,313 \\
Prova objetiva individual & $-0,177$ & 0,512 \\
Apresentação de seminários em grupo & $-0,280$ & 0,293 \\
Debates em grupo em sala de aula & $-0,160$ & 0,555 \\
Participação em sala de aula & 0,068 & 0,802 \\
\hline
\end{tabular}

Desse modo, o agrupamento foi dividido em duas categorias. A primeira, denominada 'categoria grupo', englobou as atividades que exigiam trabalho em grupo e produção escrita, a saber, a prova dissertativa em grupo, o trabalho dissertativo em grupo, a apresentação de seminários em grupo e os debates em grupo. A segunda, chamada de 'categoria individual', incluiu as atividades que exigiam não somente a produção escrita, mas também que a atividade fosse realizada individualmente, a saber, a prova dissertativa individual, os resumos de livros/capítulos e o trabalho dissertativo individual.

Recorreu-se à prova de correlação de Pearson, sendo que os índices de correlação entre o desempenho acadêmico e os escores do Cloze foram correlacionados com as médias das porcentagens de escolha por tipo de avaliação, considerando o agrupamento realizado (categoria grupo e categoria individual). A dispersão dos índices de correlação entre o desempenho acadêmico e os escores do Cloze e as médias das porcentagens de escolha por tipo de avaliação agrupados pode ser observada na Figura 2.

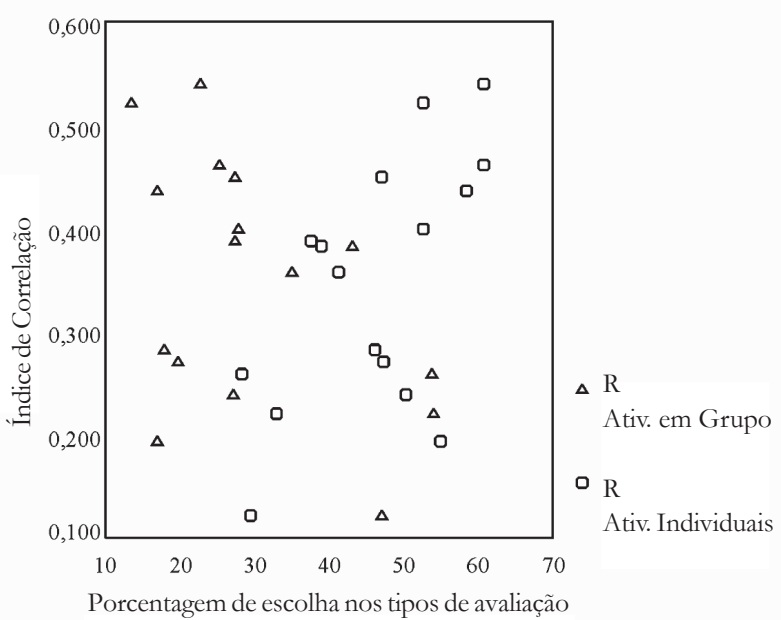

Figura 2. Dispersão dos índices de correlação entre o desempenho acadêmico e os escores do Cloze e as médias das porcentagens de escolha por tipo de avaliação agrupadas.

Os resultados apontaram que as disciplinas que exigiam uma produção escrita e cujo trabalho era essencialmente individual se correlacionaram positivamente aos coeficientes de correlação do Cloze e do desempenho acadêmico $(r=0,598 ; p=0,014)$. O inverso também foi observado, tendo em vista que as disciplinas cujo trabalho era realizado em grupo apresentaram uma tendência negativa de correlação entre as variáveis, sendo que o nível de significância não foi estatisticamente siginificativo $(r=-0,456 ; p=0,076)$.

\section{Discussão e Conclusões}

A compreensão em leitura é uma área com muitas possibilidades de pesquisa, como apontam Kardash e Howell (2000), envolvendo um complexo jogo entre o leitor e as características do texto. Para entender essa complexidade é 
necessário levar em consideração as muitas características do leitor, o conhecimento anterior que influencia a compreensão geral do texto, o objetivo da leitura e o propósito e nível de motivação do leitor. Isso talvez explique porque pesquisar a compreensão em leitura seja desafiador para os interessados pela área, devendo-se lamentar apenas que por envolver questões muito complexas, não seja possível abranger todas as variáveis que certamente estão relacionadas à essa habilidade.

Pode-se concluir que a relação entre compreensão em leitura e desempenho acadêmico foi estabelecida, considerando que o escore do Cloze se correlacionou ao desempenho acadêmico, na maioria das disciplinas. Esse dado vem corroborar estudos anteriormente realizados por Santos (1990a, 1990c, 1991), Vincentelli (1999), Oliveira (2001), entre outros, cujas pesquisas também evidenciaram essa relação.

A matemática básica foi a única disciplina do curso de administração que não apresentou correlação com o escore do Cloze, mas esse resultado já era esperado, tendo em vista que se trata de uma disciplina que exige um conhecimento técnico matemático e que, para a qual a obtenção do êxito depende menos da leitura do que de habilidades matemáticas específicas.

No curso de direito o desempenho da disciplina introdução aos estudos de direito não se correlacionou significativamente com a compreensão em leitura. Chama atenção esse fato, pois trata-se de uma disciplina cujo desempenho é obtido predominantemente por meio da leitura. Situação semelhante ocorreu no estudo realizado por Oliveira (2001), no qual não foi encontrado relação entre compreensão e leitura e desempenho acadêmico em disciplinas, cujo desempenho também era obtido por meio da leitura. Isso talvez possa estar ligado ao padrão de exigência do professor na correção ou na elaboração da prova.

No que concerne à caracterização dos tipos de avaliação mais freqüentemente utilizados pelos professores que ministram as disciplinas de conteúdos específicos nos cursos analisados, os resultados evidenciaram que o tipo mais apontado pelo estudante como aquele que o docente utiliza para mensurar o seu desempenho foi a prova dissertativa individual e o menos utilizado foi prova objetiva em grupo. As atividades individuais foram mais utilizadas em relação às tarefas que exigiam trabalho em grupo.

Ao se analisar a relação entre a compreensão de leitura e o desempenho acadêmico resultante da avaliação utilizada em disciplinas específicas, os dados indicaram que tal relação pode ser estabelecida à medida em que se procedeu ao agrupamento dos tipos de avaliação nas categorias 'grupo' e 'individual'. Desse modo, observou-se que à medida em que aumenta a média de citações de atividades individuais de avaliação o índice de correlação com o escore do Cloze e do desempenho acadêmico também aumenta.

Nesse sentido, pode-se concluir que a exigência de uma atividade individual como forma de avaliação está relacionada com uma boa compreensão em leitura e um bom desempenho acadêmico. Esses dados vêem confirmar a hipótese, levantada na pesquisa realizada por Oliveira (2001), que pressupunha que a existência de relação entre essas variáveis.
Das várias questões que não puderam ser respondidas no âmbito deste trabalho, em função de suas limitações, algumas merecem ser mencionadas. A primeira está relacionada à necessidade de se investigar sobre a possível relação entre o rigor do professor na elaboração ou correção da prova. Se tivesse sido estudado o nível de exigência das avaliações, o rigor do professor na elaboração ou correção da prova, poder-se-ia verificar se tal rigor estaria relacionado ao êxito ou fracasso do estudante na avaliação da aprendizagem. Seria interessante saber se as tendências de correlação se manteriam positiva para os tipos de avaliação que exigem empenho individual e negativa para as que são realizadas em grupo, em razão da exigência do professor.

De forma geral, espera-se que o professor procure equilibrar a avaliação realizando atividade individuais e em grupo, mas o que foi observado é que a maioria das atividades realizadas são individuais. O trabalho em grupo também deveria ser enfatizado. No entanto, deve-se ressaltar que grupos muitos numerosos não funcionam, visto que geralmente há alunos que se envolvem mais e outros menos na realização dos trabalhos, ficando difícil precisar o real aproveitamento de cada um. O ideal seria que houvesse um equilíbrio na realização de atividades individuais e em grupo, sendo preocupante perceber que o universitário em fase de preparação profissional apresente menor rendimento quando está em grupo, visto que grande parte das atividades profissionais dependem do bom entrosamento do trabalho de equipes.

Outro apontamento a ser realizado, refere-se à escassez de pesquisas sistemáticas sobre a avaliação da aprendizagem, que visem a ampliação do conhecimento na área. As considerações trazidas pelos autores são de ordem teórica e poucos são os estudiosos que realizam pesquisas com estudantes ou professores, a fim de apresentar dados mais objetivos e consistentes para serem discutidos. Assim, com as questões que ainda permanecem pendentes, sugere-se que novas pesquisas sobre o tema sejam realizadas para que o conhecimento produzido possa contribuir para a melhor compreensão do processo ensino-aprendizagem.

\section{Referências}

Almeida, A. M. F. P. M. (1992). Um estudo sobre a avaliação da aprendizagem em um curso superior de ciências agronômicas. Tese de Doutorado não-publicada, Faculdade de Educação, Universidade Estadual de Campinas. Campinas, SP.

Almeida, A. M. F. P. M. (1997). Avaliação da aprendizagem e seus desdobramentos. Avaliação, 2(2-4), 37-50.

Buriasco, R. L. C. (2000). Algumas considerações sobre avaliação educacional. Avaliação Educacional, 22, 155-178.

Camargo, A. L. C. (1997). O discurso sobre a avaliação escolar do ponto de vista do aluno. Revista da Faculdade de Educação do Rio de Janeiro, 23(1-2).

Centofanti, E. M., Ferreira, S. M. \& Del Tedesco, T. (1997). Compreensão da leitura por universitários de psicologia. Em G. P. Witter (Org.), Leitura e universidade (pp. 33-60). Campinas,SP: Alínea.

Carelli, A. E. (2002). Produção cientifica em leitura: dissertações e teses (1990-1999). Tese de Doutorado não-publicada, Centro de Ciências da Vida, Pontifícia Universidade Católica de Campinas. Campinas, SP.

Carelli, M. J. G. (1996). Perfil sócio cultural e condições de estudo em alunos da Universidade São Francisco. Dissertação de Mestrado não-publicada, Faculdade de Filosofia, Ciências e Letras, Universidade São Francisco. Bragança Paulista, SP.

Cony, C. H. (1998). A nova classe dominante. Revista República, 17, 31. 
Depresbiteris, L. (1997). Avaliação da aprendizagem: Revendo conceitos e posições. Em C. P. Sousa (Org.), Avaliação do rendimento escolar (6 $6^{\mathrm{a}}$ ed.; pp. 51-79). Campinas: Papirus.

Drouet, R. C. R. (1995). Distúrbios da aprendizagem. São Paulo: Ática.

Ellis, A.W. (1995). Leitura, escrita e dislexia: Uma análise cognitiva (2 ${ }^{\mathrm{a}}$ ed; D. Batista, Trad.). Porto Alegre: Artes Médicas.

Esteban, M. T. (2000). Exigências democráticas/exigências pedagógicas: Avaliação. Tecnologia Educacional, 29(148), 3-6.

Franco, M. L. P. B. (1997). Pressupostos epistemológicos da avaliação educacional. Em C. P. Sousa (Org.), Avaliação do rendimento escolar (6 $6^{\mathrm{a}}$ ed.; pp. 13-26). Campinas, SP: Papirus.

Garrido, E. (1988). O ensino da filosofia no $2^{\circ}$ grau e a compreensão de textos: Um levantamento em São Paulo e uma aplicação da técnica Cloẓe. Tese Doutorado não-publicada, Faculdade de Educação, Universidade de São Paulo. São Paulo, SP.

Gregoire, J. \& Piérart, B. (1997). Avaliação problemas de leitura: Os novos modelos teóricos e suas implicações (M. R. B. Osório, Trad.). Porto Alegre: Artes Médicas.

Gronlund, N. E. (1979). O sistema de notas na avaliação do ensino (I. S. Grunwaldt, Trad.). São Paulo: Pioneira.

Kardash, C. M. \& Howell, K. L. (2000). Effects of epistemological beliefs and topic-specific beliefs on undergraduates' cognitive and strategic processing of dual-positional text. Journal of Educational Psychology, 92, 524-535.

Kasai, R. C. B. (2000). Avaliação da aprendizagem: Um projeto vivido. Revista Diálogo Educacional, 1(2), 41-49.

Kopke $\mathrm{F}^{\circ}$., H. (2001). Estratégias em compreensão da leitura: Conbecimento e uso por professores de língua portuguesa. Tese de Doutorado não-publicada, Programa de Pós-graduação em Lingüística, Faculdade de Filosofia, Letras e Ciências Humanas, Universidade de São Paulo. São Paulo, SP.

Martins, R. C. (1999). Avaliação crítica de uma experiência de ensino aprendizagem. Estudos de Psicologia, PUC-Campinas, 16(2), 54-64.

Oliveira, M. H. M. A. (1996). Funções da leitura para estudantes de graduação. Psicologia Escolar e Educacional, 1(1), 61-68.

Oliveira, K. L. (2001). Compreensão, leitura e desempenho acadêmico com conteúdos específicos no curso de psicologia. Trabalho de Conclusão de Curso não-publicado, Curso Psicologia do Centro de Ciências Humanas e Sociais da Universidade São Francisco. Itatiba, SP.
Pellegrini, M. C. K. (1996). Avaliação dos niveis de compreensão e atitudes frente a leitura em universitários. Dissertação de Mestrado não-publicada, Faculdade de Ciências Humanas, Universidade São Francisco. Bragança Paulista, SP.

Santos, A. A. A. (1990a). Leituras entre universitários: Diagnóstico e remediação. Tese Doutorado não-publicada, Programa de Pós-graduação em Psicologia, Instituto de Psicologia, Universidade de São Paulo. São Paulo, SP.

Santos, A. A. A. (1990b). Compreensão em leitura na universidade: Um estudo comparativo entre dois procedimentos de treino. Estudos de Psicologia, 7(2), 3953.

Santos, A. A. A. (1990c). Leitura e universidade: Uma análise de algumas questões críticas. Trans-in-formação, 2(2-3), 91-104.

Santos, A. A. A. (1991). Desempenho em leitura: Um estudo diagnóstico da compreensão e hábitos de leitura entre universitário. Estudos de Psicologia, 8(1), 6-19.

Silva, Z. B. (2001). O processo avaliativo na aprendizagem baseada em problemas: Um estudo com alunos de medicina. Dissertação de Mestrado não-publicada, Faculdade de Ciências Humanas, Universidade São Francisco. Bragança Paulista, SP.

Sousa, C. P. (1997). Avaliação do rendimento escolar: Sedimentação de significados. Em C. P. Sousa (Org.), Avaliação do rendimento escolar (6a ed.; pp. 143-151). Campinas,SP: Papirus.

Teberosky, A. \& Cardoso, B. (1993). Reflexões sobre o ensino da leitura e da escrita (5 ed.). Petrópolis, RJ: Vozes.

Veríssimo, L. F. (1995). Desentendimento. Ícaro Revista de bordo da Varig,136(Ano XII), 11.

Vicentelli, H. (1999). Problemática de la lectura en estudiantes universitarios. Psicologia Escolar e Educacional, 3, 195-202.

Witter, G. P. (1996). Avaliação da produção científica sobre leitura na universidade. Psicologia Escolar e Educacional, 1, 31-37.

Witter, G. P. (1997). Leitura e universidade. Em G. P. Witter (Org.), Leitura e universidade (pp. 9-18). Campinas, SP: Alínea.

Recebido: $21 / 10 / 2003$

Aceite final: $23 / 12 / 2003$

Katya Luciane de Oliveira é Psicóloga, Mestre em Psicologia pelo Programa de Pós-Graduação Stricto-sensu em Psicologia, da Universidade de São Francisco, Doutoranda em Psicologia, Desenvolvimento Humano e Educação pela Universidade Estadual de Campinas e Docente do curso de Psicologia da Universidade de São Francisco e da Universidade de Alfenas.

Acácia Aparecida Angeli dos Santos é Psicóloga, Doutora em Psicologia Escolar e do Desenvolvimento Humano pela Universidade de São Paulo. É docente do curso de psicologia e do Programa de Pós-graduação Stricto-sensu em Psicologia, da Universidade São Francisco. É Bolsista produtividade do CNPq. 